\title{
A day in the life of a Ménière's patient: understanding the lived experiences and mental health impacts of Ménière's disease
}

\section{Authors:}

Sarah L. Bell ${ }^{a}$, Jessica Tyrrell ${ }^{b}$, Cassandra Phoenix ${ }^{c}$.

${ }^{a}$ European Centre for Environment and Human Health, University of Exeter Medical School, Knowledge Spa, Truro, Treliske, TR1 3HD, United Kingdom Email address:

\section{Sarah.Bell@exeter.ac.uk}

${ }^{\mathrm{b}}$ European Centre for Environment and Human Health, University of Exeter Medical School, Knowledge Spa, Truro, Treliske, TR1 3HD, United Kingdom Email: J.Tyrrell@exeter.ac.uk

${ }^{\mathrm{C}}$ Department for Health, University of Bath, Bath, BA2 7AY, United Kingdom Email address:

C.Phoenix@bath.ac.uk

\section{Corresponding author:}

Sarah L. Bell'European Centre for Environment and Human Health, University of Exeter Medical School, Knowledge Spa, Truro, Treliske, TR1 3HD, United Kingdom Email address: Sarah.Bell@exeter.ac.uk Tel: +44 1872258165 
Abstract: Concepts of social practice are increasingly being used to understand experiences of everyday life, particularly in relation to consumption and healthy lifestyles. This paper builds on this in the context of lives disrupted and reshaped by chronic illness. It uses social practice theory to examine the lived experiences of individuals with Ménière's disease; a long-term progressive vestibular disorder, defined by episodes of severe and debilitating vertigo, aural fullness, tinnitus and sensorineural hearing loss. Drawing on the findings of 20 in-depth narrative interviews with Ménière's patients, and eight spousal/partner interviews, we explore the impacts of the condition on sensory, temporal, spatial and social dimensions of the body. In doing so, we highlight the intensely embodied sensory and emotional work required to maintain connections between the 'competences', 'materials' and 'meanings' that constitute and sustain the performance of both mundane and meaningful social practices over time. As connections between these elements of social practice are disrupted during more active phases of the condition, affected individuals may be defected from old practices and recruited to new ones, often requiring both time and social support to find meaning or pleasure in these alternative ways of being in the world.

Keywords: everyday life, social practices, chronic illness, Ménière's disease, in-depth interviews 


\section{Introduction}

Ménière's disease is a long-term progressive vestibular disorder, defined by episodes of severe vertigo, aural fullness, tinnitus and fluctuating hearing loss. It has a prevalence of approximately $0.25 \%$ in the United Kingdom, equating to around 162,000 people (Tyrrell et al., 2015), and is experienced as a debilitating condition, with patients often reporting feelings of anxiety, isolation and reduced quality of life (Kirby and Yardley, 2008).

Whilst studies have examined the incidence of adverse mental health amongst Ménière's patients (for example, Yardley et al., 2003; Levo et al., 2012), we still know relatively little about how the condition is experienced in the specific contexts of people's everyday lives; how and why are symptoms experienced as disruptive and debilitating? How do people adapt to the daily practice of managing an unpredictable body and associated shifts in the spatio-temporal ordering of their lives? Much of the chronic illness literature conceptualises the onset of illness as a "biographical disruption" (Bury, 1982) or, for some, biographical "flow" or "reinforcement" (Faircloth et al., 2004). Those studies focus on the impacts of chronic illness on historical or biographical time, rather than everyday clock or perceived time. We focus on the latter, recognising the salience of these more "mundane" senses of time as people negotiate their everyday lives (Richardson et al., 2008). Unlike previous work on the lived experiences of chronic illness, we draw on social practice theory to examine how people's everyday routines shift due to Ménière's disease and how this, in turn, impacts upon their sense of wellbeing as they adapt and reorder their lives to its patterns. 
Social practice theory and chronic illness

Sociologists have been interested in both the mundane and meaningful experiences of everyday life since the 1950s, with much subsequent work underpinned by concepts of habit and practice (Bourdieu, 1990; Giddens, 1984; de Certeau, 1984). Most recently, social practice theory has been applied to issues such as sustainable consumption (Shove et al., 2012; Southerton, 2013) and healthy lifestyles (Nettleton and Green, 2014; Twine, 2015).

Building on early definitions, practices are commonly viewed as patterned, habitual social phenomena (Will and Weiner, 2014), contingent on diverse social and material dynamics (Cohn, 2014), and often interconnected with other practices and practice trajectories (Maller, 2014). According to Blue et al. (2014), the enactment of social practices involves the ongoing interaction of at least three types of elements: (1) socio-culturally shared meanings about how and why to do things; (2) the specific materials required, including objects, bodies and infrastructures; and (3) tacit and explicit competences (knowledge and embodied skills) (Maller, 2015).

A practice is sustained and reproduced through its repeated performance over time; whilst each practice performance constitutes an observable behaviour or action, the underlying practice elements (competences, materials and meanings) tend to remain somewhat invisible to the observer (Spurling et al., 2013). Drawing this distinction between practice performance and practice elements is important to ascertain how and why social practices might shift over time. With a change in (or a disconnect between) competences, materials and/or meanings, the ability to reproduce a particular practice through repeated performance may be compromised. For example, a shift in embodied skills ("competences") 
with chronic illness onset might reconfigure practice elements in a way that hinders continued enactment of that particular practice.

The aim of this paper is not to review or critically appraise the development of theories relating to social practice (this has been undertaken elsewhere, for example: Shove et al., 2012; Veenstra and Burnett, 2014). Rather, we aim to examine how the onset and progression of chronic illness can serve to reconfigure everyday social practices, interrupting the "sameness of everyday life and its rhythmic quality" (Rinkinen et al., 2015: 874).

Recognising the day as "a composite of practices" (Southerton, 2006: 440), such disruptions are explored in the context of the daily lives of people living with Ménière's disease. In so doing, we explore a context in which social practice theory has rarely been applied to date; experiences of progressive chronic illness.

\section{Methods}

The paper forms part of a wider interdisciplinary study that aimed to understand how Ménière's disease impacts upon people's mental health and wellbeing. Two complementary methods were used at different phases of the study, combining populationlevel insights from the UK Biobank (in Phase I - see Tyrrell et al., 2015) with the first-hand accounts of individual Ménière's patients (in Phase II). This paper reports on the findings from Phase II, in which in-depth qualitative methods were used to explore how and why people's everyday lives are re-choreographed following the onset of this chronic illness. We discuss how affected individuals are recruited to alternative social practices as they learn to navigate a "routinely unpredictable" life; a life in which routine activities are often 
"temporally and even spatially modified, interrupted, discontinued or cancelled as a result of the bodily realities with which they were living on any particular day" (Crooks, 2010: 51).

After securing ethical approval from the University of Exeter Medical School Research Ethics Committee (Approval Reference 13/09/029), in-depth narrative interviews were conducted from January to July 2015 with a purposive sample of 20 Ménière's patients. Each had experienced symptoms (vertigo, tinnitus, aural fullness, compromised hearing) to varying degrees within the previous 12 months. Purposive sampling ensured diverse "information-rich" views were gained from across a population of interest, allowing deeper understanding of the full complexity of a given issue, and informing analytical rather than statistical processes of generalisation (Flyvberg, 2006). Individuals were recruited from across the south west of England with the assistance of the Ménière's Society (via their "Spin" magazine, Facebook, Website, and Twitter) and via snowball sampling (Sparkes and Smith, 2014).

The sample included participants at different stages of the condition: four male and 16 female, aged between 30 and 75 years, and experiencing Ménière's symptoms in one or both ears. To some extent, that the participants were mostly female aligns with prevalence; the condition is known to affect approximately twice as many women than men (Tyrrell et al., 2015). Seven participants had received their diagnosis within the last five years and 13 had been diagnosed at least six years ago. Most were diagnosed between the ages of 40 and 60 (reflecting the typical age of Ménière's diagnosis), but three were diagnosed earlier (between the ages of 17 and 30) and two later (between the ages of 60 and 70).

During four of the patient interviews, participants' partners were present, and participants often encouraged their active involvement during the interview (Polak and 
Green, 2015). An additional eight interviews were carried out with other participants' partners to explore the impact of Ménière's on close relationships and shared daily routines. Although interview guides were developed to inform the interview process, the questions were employed flexibly, alongside active listening approaches, to encourage participant-led, open-ended responses and rich experiential descriptions (Holstein and Gubrium, 1995).

All interviews were undertaken at a time and place of participants' choosing, each lasting between 1 and 3.5 hours. The interviews were recorded digitally, transcribed verbatim (with pseudonyms used to maintain participant anonymity), and all participants were sent a copy of their transcript as part of a member-checking process (Tracy, 2010). This was followed by a period of data immersion, listening back to the recordings and annotating, reading and re-reading each transcript, noting down initial codes and emerging themes. The transcripts and a working coding framework were then uploaded to NVivo 10 (qualitative data management software) where the data were subjected to inductive thematic narrative analysis (Riessman, 2008). This stage of analysis developed and expanded on the working coding framework drafted during the immersion phase in order to capture more nuanced themes apparent within the data.

Particular care was taken to identify where themes appeared in each participant's life story, and the interactions/interplay between themes (Sparkes and Smith, 2014). This analytical approach offered insights into how participants' life stages and trajectories shaped their experiences of Ménière's disease (Phoenix et al., 2010; Bell et al., 2016). The emerging findings and interpretations were shared and discussed with a local Ménière's support group with nine attendants in order to explore resonance with their personal understandings, experiences and perceptions. Through this process, we became 
increasingly sensitised to the importance of attending to people's mundane everyday practices. We therefore returned to the transcripts to conduct a further layer of analysis examining shifts in the three core elements of social practice performance; competences, materials and meanings.

\section{Life with a "dys-appearing" body}

Before discussing the specific shifts in participants' everyday practices with the onset of Ménière's, we briefly introduce two core facets of the condition that underpinned many of the challenges faced; its unpredictability and relative invisibility compared to better-known chronic illnesses. These facets contributed to bodily "dys-appearance" (Leder, 1990); a sensation emerging as bodily know-how - typically operating on a pre-reflective level becomes disrupted and disordered, cutting through the predictability of bodily experience and bringing the body problematically to the foreground of consciousness (Becker, 1997; Zeiler, 2010). In this way, the body becomes an unfamiliar, unknown and uncontrollable terrain, with particular distress linked to newly "open" bodies; bodies that have started to "leak" and "fail" (England and Dyck, 2011).

Several participants emphasised the difficulties of living with such unpredictable open bodies; an experience described by Frank (2013: 56) as "living with perpetual interruption". As with many chronic illnesses, participants felt uncomfortable and fearful of the "immutable permanence" of this uncontrollable chronicity (Bishop and Allen, 2010: 249). Fears were magnified by the sudden onset of symptoms and the unpredictable progression of the condition. Particular concerns were linked to the occurrence of vertigo and its many expressions. One participant likened it to the flux at the seashore, explaining: 
Richard: "I describe it like waves on a seashore; either you get little waves, little ripples or a fairly still sea and you're, you're okay. But every so often, for reasons which I think are difficult to understand... the waves get bigger and bigger, and you go through quite severe vertigo, tinnitus and disorientation. And then it, over a period of time - which can take some days or weeks - it starts to settle down again. The thing that's worrying about once you're in the condition is when it's going to impact again".

Common to all the interviews were concerns about how and when the "bigger waves" of Ménière's would roll in, how long participants would be living with such severe vertigo episodes, and whether symptoms would progress to their second ear (i.e. a bilateral shift). Regular occurrence of severe vertigo attacks, which left participants unable to move, often with relentless vomiting and, for some, a loss of bowel control, perpetuated feelings of embodied vulnerability. Safety concerns were particularly apparent amongst participants who had experienced drop attacks (also known as Tumarkin attacks, present in about $10 \%$ of Ménière's cases according to Harcourt et al., 2014). These attacks - which were likened to the force of being hit by a fast-moving train whilst standing on the edge of a railway platform - occurred with no warning, thereby hindering efforts to engage in safekeeping and deterring the performance of previously taken-for-granted practices such as driving.

The everyday implications of the anxieties stemming from these different attacks resulted in a significant loss of confidence, independence and a deep sense of frustration, particularly for participants whose symptoms were not alleviated with medication. As one participant (Yvonne) said, "How do you handle it? How do you get on top of it? Can I shoot at it with a machine gun? Can I talk to it? What can I do?" This sense of powerlessness 
extended to partners and close family; as noted by Kosciulek (2010: 77), "coping rarely takes place in a social vacuum - many stressful events of daily living involve other persons". Participants expressed resignation that, short of ensuring their partner's physical safety, little could be done to stem the progression of an attack or the Ménière's in general:

David: "I guess it's also a feeling of powerlessness... because when she [David's wife] does have an attack, I can't do anything anyway. Well I can help, I can be there, but in a way, she's better just sitting still. So then ((pause)), then you just have to deal with it".

Learning to live with diminished bodily control influenced the extent to which participants felt able to adjust to the condition (Frank, 2013). For some, this process was hindered by the negative reactions of others to their "non-conforming" unfamiliar bodies; a form of "social dys-appearance" enhanced by the disapproving gaze of unknowing publics (Groven et al., 2013). As commented by Richard:

Richard: “Unfortunately, it does replicate itself by you looking like you're drunk because you're wobbly, you're being sick, you're clutching onto things, you're incoherent. And so it can be embarrassing... and you feel, you feel ((pause)) dirty really as well".

Participants' social embarrassment regarding their physical state and the risks of it being conflated with inebriation represent a form of "felt stigma", akin to that experienced by epilepsy sufferers following seizures (see Kilinç and Campbell, 2009).

Experiences of social dys-appearance also emerged in response to the disbelieving gaze of others when participants tried to raise awareness of the wider suite of externally invisible symptoms punctuating their lives on a day-to-day basis. Since hearing loss, 
hyperacusis (high sensitivity to sudden, irregular sounds), tinnitus and general disorientation are rarely externally apparent, few people seemed to understand the full extent of the condition (see Bell, 2016). As one participant (Susan) commented, "actually the fact there are so many components also contributes to the lack of understanding. You know, how can you not hear me and yet be sensitive to sound?" The lack of public awareness of these routine embodied challenges (beyond those who had witnessed attacks) led to feelings of isolation and frustration, with one participant (Emily) describing it as "Planet Ménière's". Reflecting wider literature on the challenges of living with medically unexplained syndromes and contested conditions (Nettleton et al., 2005; Nettleton, 2006; Crooks, 2007), frustrations were most apparent when participants were exposed to people who trivialised symptoms. Particular irritation was expressed at the tendency to conflate Ménière's with "feeling a bit dizzy"; as another participant (Becky) commented, it is more like "something has gone wrong with the physics of gravity".

Whilst Ménière's is not necessarily a life threatening condition, it was therefore experienced by many participants as a 'world threatening' condition (Kitzmüller et al., 2013). As one participant (Chloe) commented; "it's not life threatening but it's life shattering - it completely ruins your life when you're in it, and it seems quite hard to find a light at the end of the tunnel". We explore this further in what follows, focusing specifically on how it reconfigures the so-called "routinisation" of bodily experience (Becker, 1997).

\section{What is it like to live within the parameters of Ménière's?}

An important aim of this study was to better understand what it is like to live with Ménière's disease. Ménière's symptoms - and the fear of symptoms (particularly severe vertigo, drop 
attacks and bilateral hearing loss) - permeated many aspects of participants' daily routines. Everyday challenges ranged from waiting for the bedroom coving to stop "dancing" before getting up in the morning, to negotiating the unsettling sensations of public and private transport, navigating the "sensory overload" of routine place interactions (e.g. crowded pavements, the lighting and layout of supermarkets and offices), and adjusting to altered social, emotional and physical relationship dynamics with close friends, partners and family. We explore such challenges here, examining how the condition acts to reconfigure the competences, materials and meanings constituting previously taken-for-granted social practices, and how this shapes recruitment to new practices over time. Although we examine each of the three elements in turn for analytical purposes, their interdependence in shaping social practice performance is apparent throughout.

\section{Competences}

The term "competence" is used in the practice literature to refer to diverse and multiple forms of understanding and practical knowledgeability (Shove et al., 2012). Reflecting the important sensory dimensions of practice (Maslen, 2015), participants' accounts illustrated how vestibular impairment brings into consciousness the invisible, pre-reflective bodily work previously undertaken by the senses to keep the body "upright". With the onset and progression of Ménière's, participants were required to develop new embodied and deliberate sensory and temporal competences to address this shift.

The importance of developing such competences was perhaps most evident in participant descriptions of their shifting morning routines since illness onset, with substantial sensory work needed to orient themselves to a seemingly "moving" world. 
Creating the time for this was considered important to prepare (physically and emotionally) for the day ahead.

Caroline: "In the mornings, what I tend to do is... follow the lines around the ceiling [the coving] because if I don't do that - this is going to sound really silly ((laughs) $)$ - the lines are just moving, they're moving... So I follow the line with my eyes and then when the line looks like it's a line and not a fuzzy line, l'll get up... because otherwise, I'll just be knocking into the wall to get to the bathroom".

Later in Caroline's interview, she described the frequent sensation of furniture, floors and walls "floating" around her. Adapting to these floating material elements shifted the temporalities of many participants' routine practices. Extra time was needed for the eyes to adjust and to find a stable benchmark (as described by Richard below), often using touch to distinguish between materialities that are objectively moving and those which seem to be moving due to participants' compromised balance function.

Richard: "Your whole orientation to the world around you has dissipated and you, you don't know where the norm is. You know that if you touch something, then that must be solid. You think, 'that's okay', if you're sitting in a chair or something because you think 'well I know what a chair's like'... but if I open my eyes, all sorts of strange things are happening".

In this way, participants worked hard to build new sensory competences that would enable them to enter into and interact with their immediate surroundings. This process of embodied learning required time, often forcing them to become consciously and deliberately slow in their bodily movements as they learnt a new way of moving and being 
in and with their changing bodies (Murray, 2000). Through reconstituting sensory knowledge in this way, participants tried to rebuild bodily trust and familiarity (Ironside et al., 2003; Kitzmüller et al., 2013).

Reflecting the wider literature on poorly understood chronic illnesses such as chronic fatigue syndrome and fibromyalgia (Crooks, 2010; Pemberton and Cox, 2014), the value of "pacing" and developing new temporal competences was apparent throughout participant narratives as a strategy for self-care. This was particularly important for managing the intense fatigue routinely encountered by participants, which many attributed to the cognitive and sensory compensation required to preserve a sense of balance with compromised vestibular function. In the extract, below, for example, a participant with Ménière's symptoms in one ear (Louisa) illustrates this with a plank analogy used by her audiologist.

Louisa: "She described being deaf in one ear as trying to walk along a plank when your balance is a hundred percent, your sight and your hearing are working together to keep you walking along that plank, and not falling off. As soon as you take one thing out of the equation, which would be half your hearing, your body is then really having to work hard to keep you walking straight and keep you upright".

Developing the embodied sensory skills to adjust to this imbalance was essential for participants to engage effectively in many of their routine social practices, and required longer hours of sleep to maintain on a regular basis. One participant (Nicola) commented, "I didn't realise how important sleep was until now", indicating that sleep had taken on a new meaning as a form of self-care since the onset of Ménière's; whilst previously neglected 
during busy periods, sleep was an increasingly prioritised practice, viewed as a protective measure against the experience of recurrent and severe symptoms. Unfortunately the sleep quality of those living with particularly loud and intrusive tinnitus was often hindered, thereby exacerbating their symptoms.

Other participants explained how their sleep was sometimes interrupted through waking up into a vertigo attack. This was a particular source of anxiety for those who were not in a relationship and who therefore had to cope with these disorientating attacks by themselves. One participant (Melissa) explained that although she had not experienced a severe attack for three years, she still rings her mother for reassurance each night before going to bed.

Melissa: "This is my big confession - I get really, I still get really scared of it happening, even though it hasn't for so long. And my worst ones have always been when l've woken up first thing in the morning, so, without any notice, you just open your eyes and ((sighs)). So, every night I call my mum and we chat. And then, I do ask her whether, I say, 'I'm not going to get dizzy tonight am I?' and she says 'No you're not going to get dizzy. I promise you won't get dizzy'... That's the kind of one thing that is sort of still, the emotional effect on me, that I still need her telling me that. I'm not sure what power she has but ((laughs) $) "$

During the interview (conducted in her home), Melissa demonstrated that she keeps a bucket, torch, anti-sickness medication and tissues next to her bed "just in case". The comfort gained by Melissa from these material tools and objects, and her adoption of these daily contingency practices, reiterates the deep sense of anxiety that lingers in the 
background of life with Ménière's (even during long-term remission phases when the performance of many other day-to-day practices has resumed).

Several participants discussed the importance of developing new temporal competences to cope during uncontrollable vertigo attacks (at night and during the day). Some participants relied upon the hope of the "before and after" to get through the most tumultuous attacks, drawing on knowledge accumulated through past attacks and monitoring shifts in their bodily sensations whilst watching the clock. Others had experienced more variable attacks and therefore preferred to take one moment at a time, removing any expectation and "riding the storm".

Dawn: "Mindfulness is probably what got me through the attacks really. Just actually completely being in that moment... I did practise that a lot... because that's all there is, this moment, when you're in that Ménière's situation... There isn't anything before or anything after at that point".

Participant frustrations about these routine sensory interruptions and the challenges of adjusting to "slow" and "fragmented" time (Ziegert et al., 2009) stemmed in part from prevalent cultural norms; "being busy and conducting practices at a fast tempo becomes symbolic of a 'full' and 'valued' life" (Southerton, 2006: 438). As participants developed the embodied sensory and temporal competences to manage their symptoms, however, they came to realise that this "fast tempo" was incompatible with their efforts to maintain a sense of wellbeing and bodily equilibrium, even whilst performing the most mundane practices of everyday life. 


\section{Materials}

The term "materials" recognises that practices are intrinsically interwoven with "things" (Shove et al., 2012), be they objects, infrastructures, tools, fleshy mobile bodies or the broader atmospheric materialities created by the interaction between these different "things". Materials may be recruited to facilitate practice performance, such as Melissa's evening ritual of bringing together her bedside contingency bucket, torch, anti-sickness medication and tissues before ringing her mother for reassurance. Alternatively, the material organisation of everyday life may create barriers to performing previously valued social practices, with public indoor and outdoor settings often supporting assumed "healthy" bodies at the expense of those with more specific socio-material needs (Freund, 2001).

The performance of social practices outside of the home was often challenged by the atmospheric materialities of previously unremarkable mobilities and socio-material settings, which were now experienced as a "sensory overload". Contributing to fears of a gradually "shrinking world", participants noted constraints in getting out independently during active phases of the condition. This was due to the combined risks of driving with compromised balance and the sense of disorientation caused by the irregular sounds, motions and visual disturbance encountered on public transport.

Emma: "I'll only do little distances so that if I have a funny attack - because I have had a funny attack when I was driving and it was so scary - I need to be within kind of limping home distance. I don't really travel more than 20 miles so that's kind of limited me... but I used to love just getting in the car, putting some music on and going for a drive... and so the world has got smaller because I feel dependent on whether other people feel like driving". 
Even once out and about, the over-stimulating sensory materialities of the built environment, including loud noises, bright lights, fast moving people or objects, and a lack of horizon to focus on, rendered participants particularly vulnerable to sensations of vertigo (Bell, 2016). This is clearly articulated by Richard in the extract below, in which he refers to supermarkets and shopping malls as "hostile environments".

Richard: "Being trapped at the far end of the supermarket... the lighting is wrong and the lines are all wrong... it's quite a hostile environment... I don't like shopping malls very much either because, you know, they're claustrophobic because you don't know where the exit is. The lines, you know, it's all hard surfaces".

Others mentioned similar difficulties in hairdressers (including disorientating changes in noise and pressure as the hairdresser moves around the ears with different styling tools), cafes and restaurants (characterised by the discordant sounds of objects and bodies such as coffee machines, smashing cutlery, crying children), the work place (and often taken-forgranted swivel chairs, weekly fire alarms, stripy carpets), and crowded streets filled with cars, buses and other mobile entities. Such difficulties reflect the value of adopting more spatialised conceptions of the body, taking care to understand how bodies are experienced and lived differently in diverse socio-material settings (Freund, 2001: 695). This links to a wider body of literature on "out of place" bodies; bodies left ill at ease within environments characterised by the "embodied norms of society" (Imrie, 2010: 30). Growing concerns have been raised about the intensity of our built environments; post-modernist designers have long prioritised productivity and rapid transit, shifting the pace of these settings to that of the "machine" rather than the "human scale" (Gehl, 2010). Whilst the "able-bodied" might 
treat their bodies as machines, intent on "filling every hour" (Pemberton and Cox, 2014), the onset of chronic illness acts as stark and sudden reminder of bodily vulnerabilities and the adverse impacts of such "sickening" schedules and spatialities (Freund, 2001).

In the face of these challenges, participants discussed the importance of finding alternative pleasures to fill the day, particularly amongst those forced out of work as a result of the condition. This often involved recruitment to different social practices - and encounters with new materials such as sewing kits, paint brushes and gardening trowels to reduce feelings of loss as past practices became too demanding. This is consistent with Lundman and Jansson's (2007: 113) finding that people living with long-term illness can gain benefits from nurturing "personal havens"; activities, places or people that bring "a sense of wellbeing, feelings of being at peace with oneself and finding relief from demands". Finding such havens offered participants a sense of relief from the tyranny of "vacuous" time, instead providing an opportunity for pleasurable immersion and "uninterrupted time" (Ziegert et al., 2009). Some participants surprised themselves with the practices and settings they had come to appreciate as a result; such practices offered a sense of relief by allowing the body to "dis-appear" momentarily as it returned to the background of their consciousness rather than "dys-appearing" into the foreground (Groven et al., 2013).

Maggie: "I'm always better if I'm outdoors. Always better if I'm outdoors. So, having been a fervent gardening hater for 36 years, I'm now becoming keen on gardening, because I actually feel great if I'm outside pottering around the garden. Don't feel ill at all... I feel, the more fresh air I get, the better... I mean, whether it's alleviating the symptoms or whether it's just helping my mental health... I think it's probably a bit of both". 
Previous studies have identified the pleasurable sensory dimensions of these relatively natural environments as therapeutic and mentally restorative (e.g. Milligan et al., 2004; Tilley, 2006). Whilst such benefits were apparent within participants' narratives, their therapeutic value should not be assumed; participants also noted the challenges of negotiating the materialities of open outdoor settings in windy conditions (describing themselves, or their affected ear(s), as "human barometers") and the need to remain conscious of their bodily movements. As one participant (Jane) commented, "gardening always involves standing on your head" (weeding, planting, digging), and the repetition of such motions could exacerbate feelings of imbalance and fatigue.

In describing their navigation of everyday environments, participants conveyed efforts to maintain a steady equilibrium, avoiding socio-material conditions that might "upset their gyros". In this way, one participant (Richard) explained that you are "quite like a metronome", becoming less spontaneous and reluctant to perform any type of practice that might create unnecessary vulnerabilities for the body or "disturb the steady state". In their efforts to "read" and thereby take steps to protect the contingent body whilst negotiating more challenging sensory settings, participants highlighted the challenges of trying to control anxiety-induced "mind games":

Maggie: "It's a constant battle, and the biggest thing is the way it plays games with your head... you have this constant inner dialogue - 'Am I feeling ok? Is that a symptom? Did things just move? Am I...?' You know, 'Yes I'm alright, don't be stupid, square up'"

Maggie's self-instruction to "square up" reflects what she later refers to as "self-therapy... convincing myself I'm fine" in the face of "embodied doubt" and uncertainty (Nettleton, 
2006). Several participants discussed their efforts to manage their anxiety in this way but noted the challenges of doing so given the tangible physical basis to their concerns. There was a sense of resignation about having to constantly self-monitor their health, reflecting Frank's (2013: 33) finding that people with chronic illness tire of having to attend to the body, or "having to be embodied", on such a regular basis. This "invisible work" (Smith, 2003) is often overlooked by all except those who live with the condition, be it themselves or via supporting affected friends or family on a day-to-day basis.

\section{Meanings}

The term "meanings" is used in the practice literature to describe the mental, emotional and motivational knowledge informing the social and symbolic significance of practice performance at any particular time (Shove et al., 2012). In what follows, we highlight how the meanings of longstanding social practices can change as links with integral materials or competences break down with the onset of chronic illness. We focus particularly on efforts made to maintain meaningful social interactions with close friends (often at an embodied personal cost), and to redefine meanings of reciprocity and intimacy as frequent bodily interruptions force the boundaries of partner/spousal relationship dynamics.

Shifting sensory and temporal competences, coupled with increasingly challenging socio-material everyday environments, often forced participants to defect from the performance of previously meaningful social practices with friends and family, particularly those involving conversation amongst large groups within disorientating settings with extensive background noise (see Bell, 2016). However, participants also discussed efforts to make trade-offs in order to engage in social practices that participants knew were important 
to friends and family, despite the negative personal repercussions of doing so. The challenge of learning to make these trade-offs is illustrated in the exchange between Caroline and her husband below.

Husband: Sometimes you do too much and it makes you worse. Everything's ok when we've got 15 people here and then the next day they don't see how bad you are...

Caroline: I do push, I do push myself.

Husband: Yeah, too much, it's been a bone of contention over the years!

Caroline: ((laughs)) I push myself to do something and then I suffer from it. Many participants indicated efforts to ensure others enjoyed themselves even if they were unable to. Maggie, for example, described a day spent cooking and preparing the house for a dinner party, only to have a vertigo attack just ten minutes before friends arrived; "so I could hear them all downstairs having fun, and I was upstairs throwing up". These experiences reflect findings in the wider literature that individuals living with invisible illnesses often try to "work through their bodily pain in order to visibly maintain identities or roles which are socially constructed as being normal when in the presence of others... in spite of bodily realities such as pain and fatigue" (Crooks, 2010: 56). In this vein, participants tried to maintain the performance of meaningful social practices, despite shifts in the materialities and competences required to do so during active phases of the condition.

Apparent throughout participants' accounts was the detrimental impact of the condition on the meanings and continued performance of emotional, physical and intellectual dimensions of intimacy between couples over time (D'Ardenne, 2004; Rolland, 2007). The loss of independence associated with severe and recurrent bouts of vertigo 
meant that many participants and their partners came to perceive Ménière's as a shared condition. One participant (Mick, whose wife had Ménière's) commented, "It's not a disease one person gets - if it's a couple, it's a disease that two people get". This construction as "our" illness has been identified as a positive coping strategy for couples adapting to life with chronic illness (Weingarten, 2013), and reflects Aasbø et al.'s (2016) notion of the "biographical we"; the establishment and maintenance of a shared life project through the performance of specific practices, gestures of reciprocity and entwined narratives. However, the "biographical we" can be increasingly challenging to sustain as the ill partner's alien and unpredictable body "forcefully challenges the emotional and physical boundaries of a couple's relationship" (Rolland, 2007: 328). As indicated by Emily in the extract below (a participant with severe and protracted Ménière's symptoms over 12 years), the growing dependence on her husband, Bob, in managing such bodily changes was not an easy adjustment.

Emily: "It changes your relationship for quite some time... I mean, he had to take me to the toilet, he had to see me on the toilet being sick into a bucket and hold me on there ((laughing and crying at the same time)). That's how bad it was. I mean, husband and wife are close but you don't always want to, you know... So it became, he was like my nurse really ((crying)). It was horrible and I am sort of quite independent, really, and I like to do all my own things, and it took all that away from me... but it took your [to husband, present in interview] independence away because - along with my independence, I took yours - because I didn't want him out of my sight because I was petrified what would happen". 
As the reciprocity of a relationship becomes imbalanced in this way, couples may try to reconstruct the meaning of reciprocity (Aasbø et al., 2016), such that small acts on the part of the ill partner are recognised as important contributions to their everyday lives together. For example, Emily's husband (Bob) described and admired Emily's determination to continue performing certain domestic practices, even when she felt too ill to stand up:

Bob: But even through all of that ((laughs)), oddly enough, she still kept on top of, like, the washing and things, you know, she'd get the washing in the washing machine. She was sort of compelled to do it, even through she was crawling around. And tumble drying, you know, she sort of had to do it. I mean occasionally she'd give me orders to do it, but most of the time she'd sort of shuffle along, like this ((demonstrates what he later refers to as the “Ménière's shuffle")).

Participant narratives also highlighted the need to reconstruct meanings of intimacy over time as Ménière's progression and its frequent bodily interruptions challenged the physical integrity and sexual intimacy of affected couples. Although only discussed explicitly by one participant, the fatigue, physical motions and state of arousal during sexual relations led to unexpected experiences of vertigo, thereby acting as a physical barrier to sexual intimacy (D'Ardenne, 2004). In the extract below, Angus hints at the difficulties of (and suggests a gendered aspect to the need to talk about) the impacts of Ménière's on this more intimate social practice.

Angus: I think it has a huge impact on your sex life, right? Because, one, I go to bed early, right? I'm worn out in the evening. I also, I've found, on occasion that ((pause)) getting in, in what have you ((hesitates)), because you're then in 
that heightened state, actually it can trigger an attack, so then you pull back from your sex life, right? And that isn't anything that's mentioned at all, you know. And as, as a bloke, it's a difficult thing to talk about, but there's nowhere near as many blokes on Ménière's forums as there are women. They don't tend to talk... there's nothing mentioned on that anywhere in the Ménière's forum".

Although Angus' wife, Karen, did not mention this physical dimension of intimacy, she did discuss the loss of emotional and intellectual intimacy as a result of his bilateral hearing loss and physical fatigue. She explained that "background noise is obviously just too much for him and it, it makes him so tired, and disorientates him... So, you know, we do spend quite a lot of time in silence which is quite sad really". As a result, she described their recruitment to new practices, finding shared "havens" that allowed alternative forms of intimate expression and connection without aggravating physical symptoms (Ek et al., 2011).

Karen: "We really like going away in our camper. That's been really good, because we can go and just sit in it somewhere and watch the world go by and it's nice and quiet... we went, the other weekend, just out for the day. It was really sunny, so we went down to the seafront. And, kind of, as we started off, I don't know, there was ((pause)) a calming feeling".

This process of finding practice compensations and forging new meanings of intimacy reflects Rolland's (2007) recognition that chronic illness forces couples to "redefine intimacy and nurturance" (2007: 341) and to "construct a new relationship with the possibilities for intimacy often very different" (2007: 338) to those that originally attracted the couple together. 


\section{Concluding remarks}

In this paper, we have illustrated the value of using social practice theory to examine how and why the onset and progression of a debilitating chronic vestibular disorder - Ménière's disease - can have such pervasive and wide-ranging impacts on people's everyday lives and routines. We have demonstrated the condition's role in reconfiguring the competences, materials and meanings constituting previously unremarkable (or mundane) social practices, from waking up the in the morning to navigating an increasingly unpredictable body around "over"-stimulating everyday settings and re-negotiating shifting social and intimate relationships. Reflecting Frank's (2013: 82) findings, participants had come to "accept some level of illness as the permanent background and intermittent foreground of their lives", both for themselves and close family members. They described the process of adjusting to life with Ménière's - and their resulting contingent or "dys-appearing" body - as a steep, often emotionally charged learning curve; requiring the identification of new ways of negotiating an increasingly unsteady world, as well as shared efforts to reconstruct meanings of reciprocity and intimacy in the context of shifting relationships.

By using social practice theory to examine the impacts of Ménière's on sensory, spatial and social dimensions of the body, this paper highlights the intense bodily and emotional work required to maintain (or forge alternative) connections between the competences, materials and meanings that constitute and sustain life's everyday routines. When connections are broken, affected individuals may be defected from old practices and/or recruited to new ones, often requiring time and social support to identify new ways of being in and with a disordered body, and to find positive meanings and alternative sources of pleasure whilst doing so. 
This work reflects long-standing calls to recognise the importance of people's sociospatial and embodied experiences within existing models of chronic illness and disability (Butler and Bowlby, 1997; Thomas, 2004). It also raises more specific implications regarding the clinical support offered to individuals to find a sense of ease and stillness within their increasingly uneasy, leaky bodies following diagnosis of such chronic and intrusive vestibular disorders. Participants in this study appreciated time spent with well-informed hearing therapists and audiologists who were able and willing to translate their knowledge of the condition into meaningful explanations of altered sensory and emotional experiences (e.g. Louisa's plank analogy). Combining this with self-management advice aimed at enhancing embodied sensory competences, re-choreographing spatio-temporal routines to minimise material sensory disturbances, and finding meaning in alternative yet pleasurable social practices, could help affected individuals in their efforts to understand and adjust to the routinely unpredictable life of Ménière's.

This is one of the first studies to examine Ménière's disease in this way and now needs to be built upon, focusing specifically on people's experiences of bilateral Ménière's symptoms; this is a particularly feared potential turning point in the condition, and there was a sense amongst the four bilateral participants in this study that the second ear could follow a different illness trajectory to that of the first. Understanding these differences could help individuals with unilateral Ménière's, and their families, to feel more prepared for this shift and its likely impacts on their routine social practices and pleasures, and to encourage health professionals, employers and others to respond with dignity to patient meanings and experiences of intrusive, chronic and progressive illness. 


\section{Acknowledgements}

Many thanks go to all the study participants for sharing their experiences; Mr. David Whinney (Ear Nose and Throat Consultant at Royal Cornwall Hospital Treliske), Clinical Project Advisor; the Ménière's Society for funding the study; and PenCLAHRC (the National Institute for Health Research Collaboration for Leadership in Applied Health Research and Care South West Peninsula) for providing follow-on funding. The views expressed are those of the authors and not necessarily those of the NHS, the NIHR, the Department of Health or the Ménière's Society. We would also like to thank the two anonymous reviewers for their valuable feedback on an earlier draft of this paper.

\section{References}

Aasb $\varnothing$, G., Solbrække, K.N., Kristvik, E. and Werner, A. (2016) Between disruption and continuity: challenges in maintaining the 'biographical we' when caring for a partner with severe, chronic illness, Sociology of Health and IIIness, 38, 782-796.

Becker, G. (1997) Disrupted Lives: How People Create Meaning in a Chaotic World, California: University of California Press.

Bell, S.L. (2016) The role of fluctuating soundscapes in shaping the emotional geographies of individuals living with Ménière's disease. Social and Cultural Geography, http://dx.doi.org/10.1080/14649365.2016.1228116.

Bell, S.L., Tyrrell, J. and Phoenix, C. (2016) Ménière's disease and biographical disruption: where family transitions collide. Social Science and Medicine, 166, 177-185. 
Bishop, M. and Allen, C.A. (2010) Coping with Epilepsy: Research and Interventions, In Martz, E. and Livneh, H. (eds) Coping with Chronic Illness and Disability: Theoretical, Empirical and Clinical Aspects, New York: Springer. pp. 241-266.

Blue, S., Shove, E., Carmona, C. and Kelly, M.P. (2014) Theories of practice and public health: understanding (un)healthy practices, Critical Public Health.

Bourdieu, P. (1990) The Logic of Practice, Cambridge: Polity Press.

Bury, M. (1982) Chronic illness as biographical disruption, Sociology of Health and IIIness, 4, 167-182.

Butler, R. and Bowlby, S. (1997) Bodies and spaces: an exploration of disabled people's experiences of public space, Environment and Planning D: Society and Space, 15, 411-413.

Cohn, S. (2014) From health behaviours to health practices: an introduction, Sociology of Health \& IIIness, 36, 2, 157-162.

Crooks, V.A. (2007) Exploring the altered daily geographies and lifeworlds of women living with fibromyalgia syndrome: A mixed-method approach. Social Science \& Medicine, $64,577-588$.

Crooks, V.A. (2010) Women's Changing Experiences of the Home and Life Inside It after Becoming Chronically III, In Chouinard, V., Hall, E. and Wilton, R. (eds) Towards Enabling Geographies: 'Disabled' Bodies and Minds in Society and Space, Surrey: Ashgate Publishing Ltd. pp. 45-62.

D'Ardenne, P. (2004) The couple sharing long-term illness, Sexual and Relationship Therapy, 19, 291-308. 
De Certeau, M. (1984) The Practice of Everyday Life, Berkeley, CA: University of California Press.

Ek, K., Ternestedt, B-M., Andershed, B. and Sahlberg-Blom, E. (2011) Shifting life rhythms: Couples' stories about living together when one spouse has advanced chronic obstructive pulmonary disease, Journal of Palliative Care, 27, 189-197.

England, K. and Dyck, I. (2011) Managing the body work of home care, Sociology of Health and IIIness, 33, 206-219.

Faircloth, C., Boylstein, C., Rittman, M., Young, M. and Gubrium, J. (2004) Sudden illness and biographical flow in narrative of stroke recovery, Sociology of Health and IIIness, 26, $242-261$.

Flyvberg, B. (2006) Five misunderstandings about case study research, Qualitative Inquiry, $12,219-245$.

Frank, A. (2013) The Wounded Storyteller, Chicago: The University of Chicago Press.

Freund, P. (2001) Bodies, Disability and Spaces: The social model and disabling spatial organisations, Disability \& Society, 16, 689-706.

Gehl, J. (2010) Cities for People, Washington: Island Press.

Giddens, A. (1984) The Constitution of Society: Outline of the Theory of Structuration, Cambridge: Polity Press.

Groven, K.S., Råheim, M. and Engelsrud, G. (2013) Dis-appearance and dys-appearance anew: living with excess skin and intestinal changes following weight loss surgery, Medicine, Health Care and Philosophy, 16, 507-523. 
Harcourt, J., Barraclough, K. and Bronstein, A. (2014) Clinical Review: Ménière's disease, $B M J, 349$, g6544.

Holstein, J.A. and Gubrium, J.F. (1995) The Active Interview, London: Sage Publications.

Imrie, R. (2010) Disability, Embodiment and the Meaning of Home, In Chouinard, V., Hall, E. and Wilton, R. (eds) Towards Enabling Geographies: 'Disabled' Bodies and Minds in Society and Space, Surrey: Ashgate Publishing Ltd. pp. 23-44.

Ironside, P.M., Scheckel, M., Wessels, C., Bailey, M.E., Powers, S. and Seeley, D.K. (2003) Experiencing Chronic Illness: Cocreating New Understandings, Qualitative Health Research, 13, 171-183.

Kilinç, S. and Campbell, C. (2009) "It shouldn't be something that's evil, it should be talked about": A phenomenological approach to epilepsy and stigma", Seizure, 18, 665-671.

Kirby, S.E. and Yardley, L. (2008) Understanding psychological distress in Ménière's disease: A systematic review, Psychology, Health and Medicine, 13, 257-273.

Kitzmüller, G., Häggström, T. and Asplund, K. (2013) Living an unfamiiar body: the significance of the long-term influence of bodily changes on the perception of self after stroke. Medicine, Health Care and Philosophy, 16, 19-29.

Kosciulek, J.F. (2010) The Social Context of Coping, In Martz, E. and Livneh, H. (eds) Coping with Chronic Illness and Disability: Theoretical, Empirical and Clinical Aspects, New York: Springer. pp. 73-88.

Leder, D. (1990) The absent body, Chicago: The University of Chicago Press. 
Levo, H., Stephens, D., Poe, D., Kentala, E., Rasku, J. and Pyykko, I. (2012) EuroQoL 5D quality of life in Ménière's disorder can be explained with symptoms and disabilities, International Journal of Rehabilitation Research, 35, 197-202.

Lundmann, B. and Jansson, L. (2007) The meaning of living with a long-term disease. To revalue and be revalued, Journal of Nursing and Healthcare of Chronic Illness in association with the Journal of Clinical Nursing, 16, 109-115.

Maller, C.J. (2015) Understanding health through social practices: performance and materiality in everyday life, Sociology of Health \& IIIness, 37, 52-66.

Maslen, S. (2015) Researching the Senses as Knowledge, The Sense and Society, 10, 52-70.

Milligan, C., Gatrell, A. and Bingley, A. (2004) 'Cultivating health': therapeutic landscapes and older people in northern England, Social Science and Medicine, 58, 1781 - 1793.

Murray, T.J. (2000) Personal Time: The Patient's Experience, Annals of Internal Medicine, $132,58-62$.

Nettleton, S., Watt, I., O'Malley, L. and Duffey, P. (2005) Understanding the narratives of people who live medically unexplained illness, Patient Education and Counseling, 56, 205-210.

Nettleton, S. (2006) 'I just want permission to be ill': Towards a sociology of medically unexplained symptoms, Social Science \& Medicine, 62, 1167-1178.

Nettleton, S. and Green, J. (2014) Thinking about changing mobility practices: how a social practice approach can help, Sociology of Health \& IIIness, 36, 239-251. 
Pemberton, S. and Cox, D. (2014) Perspectives of Time and Occupation: Experiences of People with Chronic Fatigue Syndrome/Myalgic Encephalomyelitis, Journal of Occupational Science, 21, 488-503.

Phoenix, C., Smith, B. and Sparkes, A.C. (2010) Narrative analysis in aging studies: a typology for consideration, Journal of Aging Studies, 24, 1-11.

Polak, L. and Green, J. (2015) Using Joint Interviews to Add Analytic Value, Qualitative Health Research.

Richardson, J.C., Ong, B.N. and Sim, J. (2008) Experiencing and controlling time in everyday life with chronic widespread pain: a qualitative study, BMC Musculoskeletal Disorders, 9, 1-8.

Riessman, C.K. (2008) Narrative Methods for the Human Sciences, London: SAGE Publications Ltd.

Rinkinen, J., Jalas, M. and Shove, E. (2015) Object Relations in Accounts of Everyday Life, Sociology, 49, 5, 870-885.

Rolland, J.S. (2007) In Sickness and in Health: The Impact of Illness on Couples' Relationships, Journal of Marital and Family Therapy, 20, 327-347.

Shove, E., Pantzar, M. and Watson, M. (2012) The Dynamic of Social Practice: Everyday Life and how it Changes, London: SAGE Publications Ltd.

Smith, D.E. (2003) Making Sense of What People Do: A Sociological Perspective, Journal of Occupational Science, 10, 61-64.

Southerton, D. (2006) Analysing the Temporal Organization of Daily Life: Social Constraints, Practices and their Allocation, Sociology 40, 3, 435-454. 
Southerton, D. (2013) Habits, routines and temporalities of consumption: From individual behaviours to the reproduction of everyday practices, Time and Society, 22, 3, 335355.

Sparkes, A.C. and Smith, B. (2014) Qualitative Research Methods in Sport, Exercise and Health: From process to product, Abingdon: Routledge.

Spurling, N., McMeekin, A., Shove, E., Southerton, D. and Welch, D. (2013) Interventions in practice: re-framing policy approaches to consumer behaviour: Sustainable Practices Research Group.

Thomas, C. (2004) Rescuing a social relational understanding of disability, Scandinavian Journal of Disability Research, 6, 22-36.

Tilley, C. (2006) The sensory dimensions of gardening, Senses and Society, 1, 311-330.

Tracy, S. (2010) Qualitative Quality: Eight 'Big Tent' criteria for excellent qualitative research, Qualitative Inquiry, 16, 837-850.

Twine, R. (2015) Understanding snacking through a practice theory lens, Sociology of Health \& IIIness, $37,8,1270-1284$.

Tyrrell, J., White, M., Barrett, G., Ronan, N., Phoenix, C., Whinney, D. and Osborne, N. (2015) Mental Health and Subjective Wellbeing of individuals with Ménière's: Cross Sectional Analysis in the UK Biobank, Otology \& Neurotology, 36, 5, 854-861.

Veenstra, G. and Burnett, P.J. (2014) A relational approach to health practices: towards transcending the agency-structure divide, Sociology of Health \& IIIness, 36, 2, 187198. 
Weingarten, K. (2013) The "Cruel Radiance of What Is": Helping Couples Live with Chronic Illness, Family Process, 52, 83-101.

Will, C.M. and Weiner, K. (2014) Sustained multiplicity in everyday cholesterol reduction: repertoires and practices in talk about 'healthy living', Sociology of Health \& IIIness, $36,2,291-304$.

Yardley, L., Dibb, B. and Osborne, G. (2003) Factors associated with quality of life in Ménière's disease, Clinical Otolaryngology, 28, 436-441.

Zeiler, K. (2010) A phenomenological analysis of bodily self-awareness in the experience of pain and pleasure: on dys-appearance and eu-appearance, Medicine, Health Care and Philosophy, 13, 333-342.

Ziegert, K., Fridlund, B. and Lidell, E. (2009) "Time for dialysis as time to live": Experiences of time in everyday life of the Swedish next of kin of hemodialysis patients, Nursing and Health Sciences, 11, 45-50. 